100,92 $\pm 22,61$ phút, tương đương với các tác giả khác [4],[5] và ngắn hơn so với mổ nội soi trong phúc mạc [6].

Trong NC này, có $8 \mathrm{TH}$ có động mạch bất thường bắt chéo ngang khúc nối. Những TH này đều được phẫu thuật cắt rời niệu quản dưới khúc nối, chuyển vị BT - NQ ra trước mạch máu cực dưới. Kết quả phẫu thuật đều thành công ở $8 \mathrm{TH}$ này.

Trong mổ, chúng tôi không gặp bất kỳ biến chứng nào nghiêm trọng phải dừng phẫu thuật. Gần đây, các tác giả thực hiện PTNS sau phúc mạc với số lượng lớn bệnh nhân đều ghi nhận không có biến chứng trong mổ, không có trường hợp nào phải chuyển mổ mở[7].

Kết quả có $57 \mathrm{TH}$ được đánh giá là thành công và 2 TH thất bại trong nghiên cứu này, tỉ lệ thành công là $96,67 \%$. Kết quả này tương đương với kết quả của một số tác giả khác như Nguyễn Đức Minh (2018) [2] và Soulié Michel (2001) [5]. Trong $2 \mathrm{TH}$ thất bại có $01 \mathrm{TH}$ có biểu hiện đái đục sau khi ra viện 3 tháng. BN này trước mổ có đái đục kèm $\mathrm{BC}$ niệu $(+++)$, đã được điều trị kháng sinh trước mổ. Tuy nhiên, sau mổ $\mathrm{BN}$ vẫn còn biểu hiện của nhiễm trùng niệu. $\mathrm{BN}$ này tiếp tục được điều trị bằng kháng sinh, $\mathrm{TC}$ đái đục không còn. $01 \mathrm{TH}$ thất bại khác là $\mathrm{BN}$ có thận không ngấm thuốc trên UIV trước mổ. Mặc dù không còn TCLS nhưng theo dõi trên UIV không thấy cải thiện so với trước mổ.

\section{KẾT LUÂN}

Với tỷ lệ thành công là $96,61 \%$, PT NSSPM đạt kết quả điều trị tương đương phẫu thuật mổ mở, đồng thời hạn chế được các tai biến biến chứng trong và sau mổ. Lựa chọn phẫu thuật NSSPM điều trị hẹp khúc nối BT - NQ mang lại nhiều lợi ích và có thể áp dụng rộng rãi trong điều kiện hiện nay ở Việt Nam

\section{TÀI LIÊU THAM KHẢO}

1. Ngố Đaí, Hải (2014). Đánh giá kết quả phẫu thuật nối soi sau phúc mạc tạo hình khúc nối niệu quản - bể thận kiểu cắt rời, Luận án Tiến sỹ Y học, Đại hoc Y dược Thành phố Hồ Chí Minh.

2. Nguyễn Đức, Minh, Vũ Nguyễn, Khải, $\mathrm{Ca}$, Hoàng Long (2018). Kết quả lâu dài điêu trị hẹp khúc nối bể thận - niệu quản qua nội soi sau phúc mac. Y hoc Viêt Nam, 465(1): 8-12.

3. Quaia Emilio, De Paoli Luca, Martingano Paola, et al.(2014). Obstructive uropathy, pyonephrosis, and reflux nephropathy in adults. In: Radiological imaging of the kidney, Springer: 353-89.

4. Zhang $X u$, Li Hong-Zhao, Wang Shao-Gang, et al.(2005). Retroperitoneal laparoscopic dismembered pyeloplasty: experience with 50 cases. Urology, 66(3): 514-7.

5. Soulié michel, salomon laurent, patard jeanjacques, et al.(2001). extraperitoneal laparoscopic pyeloplasty: a multicenter study of 55 procedures. the journal of urology, 166(1): 48-50.

6. jarrett thomas $w$, chan david $y$, charambura tanya c, et al.(2002). laparoscopic pyeloplasty: the first 100 cases. the journal of urology, 167(3): 1253-6.

7. chen zhi, chen xiang, qi lin, et al.(2011). retroperitoneoscopic dismembered pyeloplasty for pediatric ureteropelvic junction obstruction: a report of 85 cases. zhong nan da xue xue bao. yi xue ban= journal of central south university. medical sciences, 36(5): 430.

8. martina giorgio $r$, verze paolo, giummelli pierluigi, et al.(2011). a single institute's experience in retroperitoneal laparoscopic dismembered pyeloplasty: results with 86 consecutive patients. journal of endourology, 25(6): 999-1003.

\title{
ĐẶC ĐIỂM VÀ KẾT QUẢ ĐIỀU TRI PHẪU THUÂTT KẾT XƯƠNG BÊN TRONG Ở BÊ̂NH NHÂN GÃ̃Y KÍN MẮT CÁ WEBER B
}

\section{Đặng Minh Quang*, Đặng Hoàng Anh*, Phạm Đăng Ninh*}

\section{TÓM TẮT}

Mục tiêu: Đăc điểm và kết quả điều trị phẫu thuật kết xương bên trong ở bệnh nhân gãy mắt cá loai Weber $B$. Đối tượng và phương pháp nghiên cứu: nghiên cứu hồi cứu và tiến cứu 39 bệnh nhân được chẩn đoán gãy kín mắt cá chân Weber B điều trị bằng mổ mở kết xương bên trong tại khoa Chấn

*Bênh viên Quân y 103, Hoc viện Quân y.

Chịu trách nhiệm chính: Đặng Minh Quang

Email: minhquang.hvqy@gmail.com

Ngày nhận bài: 21.10 .2020

Ngày phản biện khoa họ: 27.11.2020

Ngày duyệt bài: 9.12.2020 thương chỉnh hình Bệnh viện Quân y 103. Kết quả: Tuổi trung bình 44,10 $\pm 14,32$ tuổi, đa số là nhóm 51 đến 65 tuổi chiếm $58,97 \%$, tiếp theo nhóm từ 21 đến 50 tuổi chiếm $30,77 \%$. Nguyên nhân gây tai nạn chủ yếu gặp là tai nạn thể thao $(46,15 \%)$ và tai nạn giao thông (38,46\%), bênh nhân nam giới $(61,54 \%)$. Bênh nhân vào viện sau tai nạn (76,92\%). Bệnh nhân được mổ sớm trong tuần đầu $(94,87 \%)$. Tỷ lệ bệnh nhẩn gãy mắt cá ngoài đơn thuần là $46,15 \%$ và̀ gãy mắt cá ngoài kết hợp với gãy mắt cá trong là $33,33 \%$. Kết quả điều trị xa sau phẫu thuật đa số có tỷ lệ khá trở lên $(93,1 \%)$. Điểm trung bình theo AOFAS là 90,82 \pm 8,3 với điểm thấp nhất là 75 và điểm cao nhất là 100 . Kết luâan: bênh nhân gãy kín mắt cá loại Weber $B$ được nhập viện sớm, phẫu thuật sớm cho kết quả xa 
sau phẫu thuật đa số là cho kết quả khá trở lên.

Tư khoá: gãy mắt cá Weber $\mathrm{B}$, điều trị phẫu thuật

\section{SUMMARY \\ CHARACTERISTICS AND OUTCOME OF INTERNAL FIXATION FOR CLOSED WEBER B ANKLE FRACTURE}

Objective: Review the characteristics and outcomes of internal fixation for closed Weber B ankle fractures. Patients and method: 39 patients with closed Weber B ankle fracture were treated by open reduction and internal fixation at the Department of Orthopaedic Trauma - 103 Military Hospital , including postpective study and retrospective study. Results: average age is $44.10 \pm 14.32$; The most common causes were traffic accident $(46.15 \%)$ and sports accident (38.46\%), There were 24 males, which accounted for $61.54 \%$. $76.92 \%$ of patients immediately taken to the hospital. The number of patients with surgery within the first week accounts for a high rate of $94.87 \%$. Simple lateral malleolus fracture and bimallelar fracture which combined the lateral malleolus and medial malleolus fractures were common, occured at the rate of $46.15 \%$ and $33.33 \%$., The excellent and good results is $93,1 \%$ according scale of AOFAS. The average score is 90.82 \pm 8.3 , with the lowest point of 75 and the highest point of 100 . Conclusion: The patients with closed Weber B ankle fracture had surgery early, the long term treatment outcomes are good.

Keywords: Weber B ankle fracture, surgical treatment

\section{I. ĐĂT VẤN ĐỀ}

Gãy mắt cá chân là loại gãy xương khá phổ biến với tần suất chấn thương vùng cổ chân ở Mỹ từ 1 triệu đến 10 triệu/năm, $15 \%$ chấn thương vùng cổ chân dẫn đến gãy xương, trong đó gãy các mắt cá chiếm đến $30 \%$ [6]. Cơ chế gãy thường là gián tiếp bởi hướng lực chấn thương và tư thế của cổ bàn chân gây ra gãy xương, tổn thương hệ thống dây chằng, thương tổn phức tạp ảnh hưởng lớn tới chức năng của khớp cổ chân. Chính vì vây đòi hỏi phải có một phương pháp điều trị đúng, phục hồi tốt giải phẫu, trả lại chức năng khớp cổ chân cho người bệnh. Có nhiêu phương pháp đánh giá, phân loại tổn thương, tuy nhiên việc đánh giá có liên quan đến phương pháp điều trị thì thông thường áp dụng phân loại Weber, Lauge-Hansen cũng đã mô tả loại gãy này và đưa ra bảng phân loại gãy theo Weber gồm 3 mức $A, B$ và $C$ [7]: loại A: gãy xương mác dưới khớp chày mác dưới (không tổn thương dây chằng chày mác dưới), loại B: gãy xương mác ngang với khớp chày mác dưới (có tổn thương dây chằng chày mác dưới hoặc không), loại C: gãy xương mác trên khớp chày mác dưới (tổn thương dây chằng chày mác dưới và màng gian cốt). Trong các loại gãy xương vùng mắt cá thì gãy mắt cá loại Weber $\mathrm{B}$ là một trong những loại gãy có tổn thương phức tạp, đa số phải phẫu thuật mới phục hồi hết các tổn thương này. Hiện nay đang có hai phương pháp điêu trị gãy các mắt cá là điêu trị bảo tồn và phẫu thuật. Phương pháp điều tri bảo tồn bằng bó bột, tuy đơn giản nhưng khó phục hồi hoàn hảo về giải phẫu, cố định không chắc và hay di lệch thứ phát, thời gian bất động lâu nên kết quả phục hồi chức năng kém. Trái lại điều trị bằng phẫu thuật ngày càng phổ biến, với các kỹ thuật kết hợp xương vững chắc, phục hồi tốt về giải phẫu, phục hồi dây chằng bị tổn thương, chỉnh được các di lệch của xương sên, khớp cổ chân được cố định vững chắc, giúp cho tập phục hồi chức năng sớm, hạn chế được các di chứng chấn thương. Chính vì vậy, chúng tôi tiến hành nghiên cứu đề tài: Đặc điểm và kết quả điều trị phẫu thuật kết xương bên trong ở bệnh nhân gãy kín mắt cá weber $b$, với mục tiểu: Mô tả đặc điểm lâm sàng và $X$ quang của bệnh nhân gã̃y kín mắt cá loại Weber B; đánh giá kêt quả điều trị phẫu thuật ở bệnh nhân gãy kín mắt cá loai Weber $B$.

\section{II. ĐỐI TƯợNG VÀ PHƯƠNG PHÁP NGHIÊN CỨU}

2.1. Đối tượng: 39 bệnh nhân gãy kín mắt cá loại Weber B thời gian từ tháng 7 năm 2015 đến tháng 11 năm 2019 tại khoa Chấn thương chỉnh hình- Bệnh viện Quân y 103.

Tiêu chuẩn lựa chọn: Các bệnh nhân tuổi từ 18 trở lên, được chẩn đoán xác định gãy kín mắt cá loại Weber $B$, được can thiệp phẫu thuật, có đầy đủ hồ sơ bệnh án, địa chỉ và số điện thoại liên lạc.

Tiêu chuẩn loại trừ: Các gãy xương bệnh lý, gãy xương ở chi có sẵn các di chứng, dị tật ảnh hưởng tới đánh giá kết quả điều trị, các trường hợp gãy mắt cá Weber $\mathrm{B}$ kèm theo gãy các xương khác vùng cổ chân, bàn chân ảnh hưởng đến đánh giá chức năng của cổ chân như: võ̃ xương gót, vỡ xương sên, những bệnh nhân không đầy đủ hồ sơ, bệnh án, phim X-quang

\subsection{Phương pháp nghiên cứu}

2.2.1. Thiêt kế nghiên cứu: nghiên cứu mô tả cắt ngang, bao gồm cả nghiên cứu hồi cứu và tiến cứu

\subsubsection{Nội dung và biện pháp thu thập} số liệu

- Quy trình nghiên cứu tiến cứu: Hỏi bệnh đề thu thập các thông tin cá nhân, nguyên nhân, thời điểm và cơ chế chấn thương, tình hình sơ cứu, điều trị như thế nào, thăm khám phát hiện các triệu chứng lâm sàng toàn thân và tại chỗ, 
chụp X-quang: xác định các tổn thương, phân loai gãy theo Weber, chọn bệnh nhân Weber $B$, kiểm tra mức độ tổn thương để chọn phương pháp và phương tiện kết xương phù hợp với từng tổn thương (mắt cá trong, mắt cá ngoài, mắt cá sau, mộng chày mác) của từng bệnh nhân, chỉ định mổ và chuẩn bị bệnh nhân trước mổ, tham gia phẫu thuật và ghi chép biên bản phẫu thuật, chăm sóc và theo dõi sau phẫu thuật, đánh giá kết quả gần, hướng dẫn tập luyện $\mathrm{PHCN}$, hẹn bệnh nhân tái khám, đánh giá kết quả xa.

- Quy trình nghiên cứu hồi cứu: Lâp danh sách $\mathrm{BN}$ theo tiêu chuẩn lựa chọn từ sổ ghi biên bản phẫu thuật và sổ thống kê $\mathrm{BN}$ ra vào viện, thu thập hồ sơ bệnh án, phim X-quang trước mổ, sau mổ, lập bệnh án nghiên cứu: ghi nhận các thông tin liên quan đến nội dung nghiên cứu bao gồm: tuổi, giới, nguyên nhân, đặc điểm tổn thương, thời điểm phẩu thuật, cách thức phẫu thuật, diễn biến gần tai vết mổ và kết quả kết xương, mời bệnh nhân đến khám: đánh giá kết quả xa dựa trên lâm sàng và phim chụp $X$ quang.

\subsubsection{Các chỉ tiêu nghiên cứu}

- Đặc điểm bệnh nhân nghiên cứu: tuổi, giới, vị trí gãy, nguyên nhân (TNGT, TNSH, TNLĐ, TNTT), thời gian: từ khi bị gãy đến khi vào viện, từ khi vào viện đến khi phẫu thuật, thời gian điều trị, thời gian khám lại.

- Đặc điểm lâm sàng, hình ảnh $X$ quang: Triệu chứng lâm sàng, phim $X$ quang khớp cổ chẩn hai tư thế thẳng, nghiêng: hình ảnh gãy mắt cá trong, gãy xương mác, gãy mắt cá sau, mức độ doãng khớp chày mác dưới, bán trật khớp chày sên, phân loại cơ chế chấn thương theo Lauge-Hansen.

- Các tiêu chí về phương pháp điều trị: thời gian từ khi bị chấn thương đến khi phẫu thuật, phương pháp kết hợp xương mắt cá trong, mắt cá sau, xương mác, cố định khớp chày mác dưới

- Đánh giá kết quả:

+ Kết quả gần: Thời gian đánh giá kết quả: 3 tuần sau phẫu thuật: Diển biến tại vết mổ, đánh giá kết quả nắn chỉnh và kết xương dựa trên phim X quang chụp khớp cổ chân sau mố.

+ Kết quả xa: Thời gian đánh giá tối thiểu 12 tháng sau mổ. Chúng tôi dựa theo bảng đánh giá kết quả điều trị của Hêe thống điểm mắt cá bàn chân sau của Hội chỉnh hình bàn chân và mắt cá của Mỹ (hệ thống điểm AOFAS - Ankle Hindfoot score).

1) Đau (40 điểm): Không đau: 40 điểm; đau nhẹ, thoảng qua, đi laai tốt: 30 điểm; đau thường xuyên, ảnh hưởng đi lại: 20 điểm; đau nhiều, cần phải hỗ trợ khi đi lai: 0 điểm.

2) Vận động chức năng (50 điểm)

Mức độ hạn chế vận động và nhu cầu hỗ trợ: Vận động bình thường: 10 điểm; chỉ hạn chế chạy nhảy: 7điểm; đi lại khó khăn, phải chống gậy khi đi: 4 điểm; không đi lại được, phải dùng nạng, xe lăn: 0 điểm.

Khoảng cách đi bô tối đa: >500m: 5điểm; 300 -500m: 4điểm, 100-300m: 2điểm, <100m: 0 điểm.

Khả năng đi trên mặt đường nghiêng, gồ ghề, lên xuống cầu thang: Đi bình thường: 5 điểm, đi lại không dễ dàng: 3 điểm, khó khăn hoặc không đi được: 0 điểm.

Dáng đi bất thường: Bình thường: 8 điểm, bước ngắn: 4 điểm, tập tễnh: 0 điểm.

Biên độ gấp + duỗi cổ chân: Bình thường hoặc hạn chế ít $\left(\geq 30^{\circ}\right)$ : 8 điểm, hạn chế mức độ trung bình $\left(15^{\circ}-29^{\circ}\right)$ : 4 điểm, hạn chế nhiều $\left(<15^{\circ}\right)$ : 0 điểm.

Biên độ sấp + ngửa bàn chân: Bình thường hoăcc hạn chế ít (75\% - 100\% bình thường): 6 điểm, hạn chế mức độ trung bình ( $25 \%-74 \%): 3$ điểm, hạn chế nhiều $(<25 \%)$ : 0 điểm.

Sự vững chắc của cổ chân: Vững: 8 điểm. Không vững: 0 điểm.

3) Trục bàn chân (10 điểm): Trục thẳng, đứng áp cả lòng bàn chân xuống đất: 10 điểm, trục tương đối thẳng, đứng áp cả lòng bàn chân xuống đất: 6 điểm, trục không thẳng, không áp được lòng bàn chân xuống đất: 0 điểm.

Tổng điểm: điểm

Phân loại kết quả: Kết quả tốt: >90 điểm, kết quả khá: 81-90 điểm, kết quả trung bình: 70 - 80 điểm, kết quả kém: $<70$ điểm.

2.2.4. Xür lý số liệu và đạo đức y học trong nghiên cứu: xử lý số liệu bằng chương trình toán thống kê SPSS 20.0; Nghiên cứu không vi phạm đạo đức y học.

\section{KẾT QUẢ NGHIÊN CỨU}

\section{1. Đặc điểm chung tổn thương ở bệnh nhân nghiên cứu}

Bảng 3.2. Phân bố theo tỷ lệ nhóm tuổi $(n=39)$

\begin{tabular}{|c|c|c|}
\hline Nhóm Tuối & Số lượng & Tỷ lệ (\%) \\
\hline $18-20$ tuối & 2 & 5.13 \\
\hline $21-50$ tuối & 12 & 30.77 \\
\hline $51-65$ Tuối & 23 & 58.97 \\
\hline Trên 65 tuối & 2 & 5.13 \\
\hline Trung bình (tuối) & $44,10 \pm 14,32$ & \\
\hline Tuôn
\end{tabular}

Tuổi trung bình 44,10 $\pm 14,32$ tuối, trong đó nhóm tuổi số lượng chiếm nhiều nhất là 51 đến 65 tuổi chiếm 58,97\%, tiếp theo nhóm từ 21 đến 50 tuổi chiếm 30,77\%. 
Bảng 3.2. Nguyên nhân gãy xương ( $n=39)$

\begin{tabular}{|c|c|c|c|}
\hline \multirow{2}{*}{$\begin{array}{c}\text { Nguyyên nhân } \\
\text { chấn thương }\end{array}$} & \multicolumn{2}{|c|}{ Giới } & \multirow{2}{*}{ Tổng (n, \%) } \\
\cline { 2 - 4 } & $\mathbf{N a m}(\mathbf{n}, \mathbf{\%})$ & $\mathbf{N u ̛ ̃}(\mathbf{n}, \mathbf{\%})$ & \\
\hline Tai nạn giao thông & $7(46,67 \%)$ & $8(53,33 \%)$ & $15(38,46)$ \\
\hline Tai nạn sinh hoạt & $3(100 \%)$ & $0(0 \%)$ & $3(7,69)$ \\
\hline Tai nạn thế thao & $12(66,67 \%)$ & $6(33,33 \%)$ & $18(46,15)$ \\
\hline Tai nạn lao động & $2(66,67 \%)$ & $1(33,33 \%)$ & $3(7,69)$ \\
\hline Tống & $\mathbf{2 4 ( 6 1 , 5 4 \% )}$ & $\mathbf{1 5}(\mathbf{3 8 , 4 6 \% )}$ & $\mathbf{3 9}(\mathbf{1 0 0})$ \\
\hline
\end{tabular}

Nguyên nhân gây tai nạn chủ yếu gặp là tai nạn thế thao với $18 / 39$ bệnh nhân chiếm tỷ lệ $46,15 \%$ và tai nạn giao thông với 15/39 bệnh nhân chiếm tỷ lệ 38,46\%. Bệnh nhân nam cao hơn nứ, tỷ lệ nam/ nữ là $1,6 / 1$.

Bảng 3.3. Điều trị trước mổ $(n=39)$

\begin{tabular}{|c|c|c|}
\hline Điều trị trước mổ & $\begin{array}{c}\text { Số lượng } \\
(\mathbf{n})\end{array}$ & $\begin{array}{c}\text { Tỷ lệ } \\
(\mathbf{\%})\end{array}$ \\
\hline Chưa xử trí & 30 & 76,92 \\
\hline Bó lá & 3 & 7,69 \\
\hline Nắn bó bột & 0 & 0 \\
\hline Nẹp cố định tạm thời & 6 & 15,38 \\
\hline
\end{tabular}

Có 30 bệnh nhân chiếm 76,92\% chưa được xử trí gì trước khi vào viện. Có 6 bệnh nhẩn được xử lý trước khi vào viện bằng cố định nẹp chiếm 15,38\%. Có 3 bệnh nhân được xử lý trước khi vào viện bằng bó lá chiếm 7,69\%.

Bảng 3.4. Thời gian tư khi bị tai nạn đến khi điều trị phẫu thuật $(n=39)$

\begin{tabular}{|c|c|c|}
\hline Thời gian & Số lượng (n) & Tỷ lệ (\%) \\
\hline$<24$ giờ & 9 & 23,08 \\
\hline 1 - 3 ngày & 20 & 51,28 \\
\hline 4 - 7 ngày & 8 & 20,51 \\
\hline >7 ngày & 2 & 5,13 \\
\hline
\end{tabular}

Hầu hểt các trường hợp được mố trong tuần đầu sau khị bị gãy xương (37/39) trường hợp chiếm $94,87 \%$.

Bảng 3.5. Cơ chế chân thương $(n=39)$

\begin{tabular}{|c|c|c|}
\hline Cơ chế & Số lượng (n) & Tỷ lệ (\%) \\
\hline Ngữa - giạng & 0 & 0,00 \\
\hline $\begin{array}{c}\text { Ngửa - xoay } \\
\text { ngoài (SER) }\end{array}$ & 15 & 38,46 \\
\hline $\begin{array}{c}\text { Sấp - Xoay } \\
\text { ngoài (PER) }\end{array}$ & 16 & 41,03 \\
\hline Không rõ tư thế & 8 & 20,51 \\
\hline
\end{tabular}

Cơ chế chấn thương xoay ngoài chiếm nhiêuu nhất với tỷ lê $79,48 \%$ trong đó ngửa -xoay ngoài chiếm $38,46 \%$ và sấp - xoay ngoài chiếm $41,03 \%$.

Bảng 3.6. Đặc điểm tổn thương xương trên XQuang ( $n=39)$

\begin{tabular}{|c|c|c|}
\hline Tổn thương & $\begin{array}{c}\text { Số lượng } \\
(\mathbf{n})\end{array}$ & $\begin{array}{c}\text { Tỷ lệ } \\
\text { (\%) }\end{array}$ \\
\hline $\begin{array}{c}\text { Gãy mắt cá ngoài } \\
\text { đơn thuần }\end{array}$ & 18 & 46,15 \\
\hline $\begin{array}{c}\text { Gãy mắt cá ngoài }+ \\
\text { mắt cá trong }\end{array}$ & 13 & 33,33 \\
\hline Gãy mắt cá ngoài + & 4 & 10,25 \\
\hline
\end{tabular}

\begin{tabular}{|c|c|c|}
\hline mắt cá sau & & \\
\hline Gãy ba mắt cá & 4 & 10,25 \\
\hline
\end{tabular}

Gãy mắt cá ngoài đơn thuần và gãy mắt cá ngoài kết hợp với gãy mắt cá trong hay gặp nhất với tỷ lệ lần lượt là $46,15 \%$ và $33,33 \%$. Gãy ba mắt cá hiếm gặp nhất chỉ có 4 trường hợp, chiếm $10,25 \%$.

3.2. Kết quả điêu trị của bệnh nhân nghiên cứu

3.2.1. Kêt quả điều trị gần. $100 \%$ bệnh nhân liền vết mố kì đầu. X-quang sau mổ: Tất cả các trường hợp đều đạt yêu cầu về chỉnh hình, hết di lệch, kểt xương đạt yêu cầu

\subsubsection{Kêt quả điều tri xa}

Bảng 3.7. Kết quả điều trị xa sau phẫu thuât $(n=29)$

\begin{tabular}{|c|c|c|c|c|}
\hline $\begin{array}{c}\text { Kết } \\
\text { quả xa }\end{array}$ & Điểm & $\begin{array}{c}\text { Số } \\
\text { lượng }\end{array}$ & $\begin{array}{c}\text { Tỷ lệ } \\
(\mathbf{\%})\end{array}$ & $\begin{array}{c}\text { Điếm trung } \\
\text { bình }\end{array}$ \\
\hline Tốt & $>90$ & 17 & $58,62 \%$ & $\begin{array}{c}95,71 \pm 2,28 \\
(93-100)\end{array}$ \\
\hline Khá & $81-90$ & 10 & $34,48 \%$ & $\begin{array}{c}85,3 \pm 2,31 \\
(81-87)\end{array}$ \\
\hline $\begin{array}{c}\text { Trung } \\
\text { bình }\end{array}$ & $71-80$ & 2 & $6.9 \%$ & $77,00 \pm 0$ \\
\hline Kém & $<70$ & 0 & $0 \%$ & 0 \\
\hline Tống & $\mathbf{1 0 0}$ & $\mathbf{2 9}$ & $\mathbf{1 0 0}$ & $\mathbf{9 0 , 8 2} \pm \mathbf{8 , 3}$ \\
\hline
\end{tabular}

Thời gian theo dõi trung bình $21,79 \pm 10,03$ tháng. Kết quả tốt và khá có $27 / 29$ bệnh nhân chiếm tỷ lệ $93,1 \%$. Chỉ có 2 bệnh nhân đạt kết quả trung bình chiếm $6,9 \%$. Không có bệnh nhân nào có kết quả kém. Điểm trung bình là $90,82 \pm 8,3$ với điểm thấp nhất là 75 và điểm cao nhất là 100 .

\section{BÀN LUẬN}

4.1. Đặc điểm chung tổn thương của nhóm nghiên cứu. Tuổi trung bình của các bênh nhân là 44,10 $\pm 14,32$ tuổi, trong đó nhóm tuổi số lượng chiếm nhiều nhất là 51 đến 65 tuổi chiếm 58,97\%, tiếp theo nhóm từ 21 đến 50 tuổi chiếm 30,77\% (bảng 3.1). Đa số các tác giả cũng nhận định chung về tổn thương gãy kín mắt cá Weber $B$ thường tập chung vào lứa tuổi $[1],[2],[3],[4]$. Nhóm tuổi từ 21 đến 65 tuổi là 
nhóm bệnh chủ yếu nằm trong độ tuổi lao động và có tham gia giao thông (tai nạn giao thông chiếm $38,46 \%)$, thể thao nhiêu nhất $(46,15 \%)$ (bảng 3.2), tỷ lệ này phù hợp so với các nghiên cứu trong nước [1],[2],[3],[4].

Trong 39 bệnh nhân chúng tôi nghiên cứu có 6/39 chiếm 15,38\% bệnh nhân đã được sơ cứu trước vào viện bằng bất động tạm thời và 76,92 \% bệnh nhân chưa xử lý gì (bảng 3.3), Số lượng bệnh nhân được phẫu thuật trong tuần đầu sau chấn thương chiếm tỉ lệ cao với 94,87\% (bảng 3.4). Tỷ lệ này phù hợp với các nghiên cứu trước đó $[1,2,3,4]$. Như vậy đa số bệnh nhân được xử trí sớm, điều này khi điều tra bệnh sử chúng tôi thấy bệnh nhân của chúng tôi đa số ở những quận, huyện gần Bệnh viện Quân Y 103 nên sau khi tai nạn được gia đình khẩn trương đưa vào thẳng bệnh viện, mặt khác với dân trí ngày càng cao, ưu điểm của phẫu thuật phục hồi chức năng sớm là nhu cầu của hầu hết người bệnh.

Đối với cơ chế chấn thương chúng tôi ghi nhận có 31/39 trường hợp gãy do cơ chế bàn chẩn xoay ngoài chiếm $79,5 \%$, trong đó có $15 / 39$ trường hợp là ngửa- xoay ngoài, 16/39 trường hợp gãy do cơ chế sấp- xoay ngoài (bảng 3.5). Cơ chế chấn thương của chúng tôi phù hợp với nghiên cứu của tác giả trong nước như của Đỗ Tuấn Anh (2016) [2] khi tỷ lệ này là $69,7 \%$. So với tác giả nước ngoài như Karande và cộng sự (2017) [5] thì cơ chế bàn chân xoay ngoài chiếm 72,2\%.

Tổn thương gãy mắt cá ngoài kết hợp với 1 mắt cá chân trong nghiên cứu của chúng tôi là gặp nhiều nhất chiếm tỷ lệ $61 \%$ (bảng 3.6). Tỷ lệ này cũng phù hợp với các nghiên cứu trước đó như nghiên cứu của Ma Ngọc Thành [2] khi tỷ lệ là 57,14\%, Nguyễn Điện Thành Hiệp [4] là 44,74\%.

4.2. Kết quả điêu trị của nhóm bệnh nhân nghiên cứu

Kết quả điều trị gần: Trong nghiên cứu của chúng tôi tất cả 39/39 trường hợp chiếm $100 \%$ $X Q$ đêu đạt giải phẫu sau mổ. chúng tôi không ghi nhận được trường hợp nào chụp XQ cổ chân sau mổ không đạt giải phẫu, hoặc đâu vít chạm vào diện khớp. Thành quả này do chúng tôi đã chủ động dùng màn tăng sáng trước khi đóng vết mổ với tất cả các trường hợp mổ gãy mắt cá để đạt được kết quả tốt nhất cho bệnh nhân. Kết quả của chúng tôi cũng tương đồng với kết quả của Nguyễn Trung Văn [3] và Đỗ Tuấn Anh [2] cũng đạt giải phẫu là $100 \%$.

Kêt quả điều trị xa: Trong số 39 bệnh nhân của chúng tôi có 29 bệnh nhân khám lại đủ điều kiện đánh giá theo thang điểm AOFAS với thời gian theo dõi trung bình 21,7 tháng. Điểm trung bình là $90,82 \pm 8,3$ với điểm thấp nhất là 75 và điểm cao nhất là 100 . Trong đó kết quả tốt và khá chiếm 93,1\% (bảng 3.7), cao hơn phần lớn kết quả trong các nghiên cứu của các tác giả.[1],[2],[3],[4]. Có được kết quả này có thể một phân là do các bệnh nhân được nhập viện sớm, phẫu thuật sớm nhanh chóng trả lại chức năng vận động cho bệnh nhân.

\section{KẾT LUÂ̂N}

- Tuổi trung bình 44,10 14,32 tuổi, đa số là nhóm 51 đến 65 tuổi chiếm 58,97\%, tiếp theo nhóm từ 21 đến 50 tuổi chiếm 30,77\%.

- Nguyên nhân gây tai nạn chủ yếu gặp là tai nạn thể thao $(46,15 \%)$ và tai nạn giao thông $(38,46 \%)$, chủ yếu là bệnh nhân nam giới $(61,54 \%)$. Đa số bệnh nhân được đưa ngay khi chấn thương và chưa được xử trí gì $(76,92 \%)$. Hầu hết các các bệnh nhẩn được mổ trong tuần đầu sau khị bị gãy xương $(94,87 \%)$.

- Đa số bệnh nhân gãy mắt cá ngoài đơn thuần $(46,15 \%)$ và gãy mắt cá ngoài kết hợp với gãy mắt cá trong là $33,33 \%$.

- Kết quả điều trị xa sau phẫu thuật đa số có tỷ lệ khá trở lên $(93,1 \%)$. Không có bệnh nhân nào có kết quả kém. Điểm trung bình là $90,82 \pm 8,3$ với điểm thấp nhất là 75 và điểm cao nhất là 100 .

Kết luận: bệnh nhân gãy kín mắt cá loại Weber $\mathrm{B}$ được nhập viên sớm, phẫu thuật sớm cho kết quả xa sau phấu thuật đa số là cho kết quả khá trở lên.

\section{TÀl LIỆ THAM KHẢO}

1. Nguyễn Văn Việt (2014). Đánh giá kết quả điều trị gãy kín Dupuytren ở người lớn bằng phương pháp kết hợp xương bên trong tại Bệnh viện ViệtTiếp. Luân văn tốt nghiệp Bác sĩ nội trú Đại học Y Dược Hải Phòng.

2. Đố Tuấn Anh (2016). Kết quả phẫu thuât gãy kín mắt cá chân ở người trưởng thành tại bệnh viện hữu nghị Việt Đức, Luận văn thạc sĩ y học Đại học Y Hà Nô̂i.

3. Nguyến Trung Văn (2019). Đánh giá kết quả phâu thuật gãy kín mắt cá chân tại bênh viên Saint Paul. Luận văn thạc sĩ y học Đại học Ỳ Hà Nội.

4. Nguyê̂n Điện Thành Hiệp (2020). Đánh giá kết quả điều trị gãy kín Dupuytren bằng phương pháp kết hợp xương bên trong tại bệnh viện Trung ước Quân đội 108. Luận văn thạc sĩ y học Học Viện Quân Y.

5. Karande V., Nikumbha V.P, Desai A. et al. (2017). Study of surgical management of malleolar fractures of ankle in adults. Int J Orthop Sci, 3(3), 783-787.

6. Daly P.J., Fitzgerald R.H., Melton L.J. et al. (1987). Epidemiology of ankle fractures in Rochester, Minnesota. Acta Orthop Scand, 58(5), 539-544.

7. Paige Whittle.A (2007) . Fracture of the lower Extremity. Campbell's operative orthopedics, 11thed, 3086- 3096. 